\title{
Ensino do Cálculo nas Engenharias: Simultaneidade do ensino do Cálculo e matemática básica.
}

DOI: 10.37702/2175-957X.COBENGE.2021.3613

Telma Crisitna Pimenta de Freitas - telmapimenta@terra.com.br UFMG

Rua Monte Carmelo 54

31015-230 - Belo Horizonte - MG

Resumo: Sabe-se que as disciplinas de Cálculo Diferencial e Integral apresentam problemas no processo de ensino aprendizagem, com elevadas taxas de evasão e reprovação. Dentre os problemas, a falta de conhecimento de matemática básica tem se mostrado relevante e recorrente. Este artigo apresenta a proposta de simultaneidade no ensino do Cálculo e da matemática básica, com o propósito de mitigar os problemas de falta de desenvoltura algébrica dos alunos. A pesquisa, realizada em uma faculdade particular, mensurou a desenvoltura algébrica de uma turma de primeiro período de engenharia, em matemática básica, antes e depois de um grupo de estudo no qual a matemática básica era ensinada simultaneamente ao Cálculo. Os resultados indicaram um progresso muito significativo na formação dos estudantes, além da afiliação dos alunos à Instituição.

Palavras-chave: Cálculo Diferencial e Integral, Ensino do Cálculo, Reprovação em Cálculo. 


\section{ENSINO DO CÁLCULO NAS ENGENHARIAS: SIMULTANEIDADE DO ENSINO DO CÁLCULO E MATEMÁTICA BÁSICA.}

\section{INTRODUÇÃO}

As disciplinas de Cálculo Diferencial e Integral apresentam altos índices de reprovação e evasão (Dorr, 2017), (Almeida 2017). Esses índices de reprovação elevados são amplamente conhecidos por professores e estudantes, ultrapassando mesmo os muros das comunidades de ciências exatas.

Dentre os problemas do ensino aprendizagem do Cálculo Diferencial e Integral, a falta de conhecimento da matemática básica e de desenvoltura algébrica dos estudantes tem se mostrado um problema relevante e recorrente (Dor, 2017), (Rafael, 2017). O problema ocorre em Instituições Públicas e privadas mas ganha agravo nas Instituições privadas, pois a seleção mais flexível dessas escolas permite o ingresso de alunos com grandes deficiências algébricas e numéricas.

Muitas propostas para a melhoria do ensino de Cálculo passa pela implementação de um curso de nivelamento: Cálculo zero, matemática básica, pré-cálculo. Qualquer que seja a designação, esta é uma proposta bastante recorrente (Rocha,2016), (Muller,2015), que pretende instrumentalizar os alunos nos conhecimentos básicos necessários ao prosseguimento do curso.

Contudo Rocha (2016), Dorr (2017), Muller (2015) dentre outros autores argumentam que esses cursos não apresentam o resultado esperado, que não existe uma aprendizagem efetiva que será utilizada na apreensão dos conceitos do Cálculo Diferencial e Integral.

Diante deste dado da literatura, propusemos que os conteúdos fossem revisados (algumas vezes ensinados) em paralelo com o ensino do cálculo, no lugar de ocuparem uma posição propedêutica.

Este projeto se deu em uma Faculdade particular de Belo Horizonte, através da implementação de um grupo de estudo de uma turma piloto do curso de engenharia.

Na próxima secção serão apresentados os pressupostos da pesquisa e seu desenho metodológico. Na seção seguinte os resultados que foram mensurados em duas provas, uma diagnóstica e outra aplicada três meses após a primeira. $\mathrm{Na}$ última seção discutiremos os resultados da pesquisa, suas limitações e desdobramentos.

\section{RESGATE DE MATEMÁTICA BÁSICA E ENSINO DE CÁLCULO DIFERENCIAL EINTEGRAL : UMA PROPOSTA DE SIMULTANEIDADE}

Os problemas do ensino aprendizagem da matemática recrudescem quando se trata do Cálculo Diferencial e Integral. Parte considerável do problema parece estar 
associado à falta de desenvoltura algébrica dos estudantes, o que dificulta a escrita e obtenção dos resultados e por que não dizer também, a apreensão de conceitos.

Se considerarmos a matemática como linguagem, e uma linguagem não precedida ou acompanhada de oralidade como é o caso da língua materna(Machado, 2011), consideramos que seria através da própria escrita que os conceitos matemáticos ganhariam corporeidade.

Nas palavras de Machado (2011), nas linguagens formais como a matemática, os significados são definidos ou caracterizados a partir de relações que estabelecem com outros, no interior do formalismo. $\mathrm{O}$ autor fornece o exemplo da teoria da relatividade. $\mathrm{O}$ exemplo é tal forma esclarecedor que vale a pena reproduzi-lo aqui:

Einstein, por exemplo, não definiu energia, massa e velocidade para, posteriormente, enfeixar tais conceitos na relação $E=m . c^{2}$, na verdade, 0 significado de cada um deles é que é construído a partir desta e de outras relações. Na elegante e arguta observação de Bachelard (1968, p.127): “ Longe se ser o ser a ilustrar a relação, é a relação que ilumina o ser" (Machado, 2011, pág118).

Vistos dessa forma os conceitos ganham "realidade" quando escritos, quando expressos na linguagem matemática, e a linguagem matemática ganha significados, deixando de ser vista apenas no âmbito da sintaxe.

Nesse sentido propusemos que as dificuldades de matemática básica fossem sanadas junto com o ensino do Cálculo Diferencial. A hipótese é que o cálculo revestiria de significados a sintaxe matemática, que por sua vez daria corporeidade aos conceitos do cálculo, em um processo de retroalimentação. Partimos também do pressuposto que o aluno de curso superior, de formação lacunar, não parte do vazio. Trata-se de refazer os hiatos deixados nessa formação entretendo uma teia rota, que precisa ser refeita. Os procedimentos algébricos vão sendo revestidos dos sentidos próprio ao Cálculo Diferencial e Integral, ao mesmo tempo que o conhecimento da linguagem matemática permite transcrever os conceitos, dotando-os de realidade.

O projeto foi realizado em uma turma de primeiro período de Engenharia, de uma Faculdade Particular de Belo Horizonte, em 2019.

Inicialmente os alunos foram convidados a participar do projeto realizando uma prova diagnóstica. Nessa prova foi detectado pela professora, autora desse artigo, as maiores dificuldades dos alunos, de forma individualizada. Essa prova diagnóstica contou com a participação de 24 alunos, dos cerca de 30 inscritos na disciplina de Cálculo Diferencial. A prova, composta de 4 questões, pretendeu mensurar conhecimentos básicos como propriedades de potências, resolução de equações de primeiro e segundo graus, hierarquia nas operações, etc. Com base no resultado foi confeccionado um mapa com o dimensionamento de cada aluno, em cada questão.

O resultado do mapa foi reportado aos alunos de modo individual, de forma que cada estudante teve acesso aos seus acertos, erros e dificuldades. Diante do diagnóstico pessoal e da possibilidade de reverter deficiências e trabalhar potencialidades, os estudantes foram instados a se envolverem em um grupo de estudos. 
O grupo de estudos se encontrou 14 vezes até a realização da segunda prova, cujo resultado foi cotejado com a primeira. Nos encontros os alunos trabalhavam em grupo, sob a orientação de dois monitores. Trabalhavam com um material confeccionado pelo professor, que mesclava matéria de Cálculo com grande utilização de matemática básica. Dos 24 alunos, 2 desistiram do curso. Não sabemos à que podemos creditar o abandono, mas provavelmente não por acaso, os dois alunos deixaram a prova diagnóstica em branco. Dos 22 restantes, 17 participaram efetivamente do grupo de estudo.

\section{RESULTADOS}

O quadro a seguir apresenta as habilidades mensuradas em cada questão e as dificuldades dos estudantes. É fácil perceber que as dificuldades são muitas e, verdadeiramente, de base.

Quadro 01: Resultado de cada aluno, por questão, na prova diagnóstica.

\begin{tabular}{|c|c|c|c|c|}
\hline Aluno & $\begin{array}{l}\text { Questão 01: } \\
\text { Mensurar se o aluno } \\
\text { conhece } \\
\text { propriedades de } \\
\text { potências e sabe } \\
\text { somar frações. }\end{array}$ & $\begin{array}{l}\text { Questão 02: } \\
\text { Pretende-se saber } \\
\text { se o aluno conhece } \\
\text { a hierarquia das } \\
\text { operações e trato } \\
\text { numérico } r \\
\text { algébrico. }\end{array}$ & $\begin{array}{l}\text { Questão 03: } \\
\text { Diferenciar variável } \\
\text { dependente de } \\
\text { independente e } \\
\text { resolver equações } \\
\text { de segundo grau. }\end{array}$ & $\begin{array}{l}\text { Questão 04: } \\
\text { Desenvoltura } \\
\text { algébrica (Eq. de } \\
\text { primeiro grau) e } \\
\text { capacidade de } \\
\text { interpretação. }\end{array}$ \\
\hline A & $\begin{array}{l}\text { Conhece as } \\
\text { propriedades. Erro de } \\
\text { cálculo e de } \\
\text { simplificações }\end{array}$ & Usou Calculadora & $\begin{array}{l}\text { Usou Calculadora. } \\
\text { Sabe resolver } \\
\text { corretamente } \\
\text { equações de segundo } \\
\text { grau. }\end{array}$ & $\begin{array}{l}\text { Erro de } \\
\text { interpretação. Bom } \\
\text { trato algébrico. }\end{array}$ \\
\hline B & \begin{tabular}{|l|} 
Não sabe as \\
propriedades. Não \\
sabe somar frações.
\end{tabular} & $\begin{array}{l}\text { Sabe a hierarquia, } \\
\text { contudo não conhece } \\
\text { as propriedades e } \\
\text { não sabe trabalhar } \\
\text { com potências } \\
\text { negativas. }\end{array}$ & $\begin{array}{l}\text { Sabe resolver } \\
\text { equação do segundo } \\
\text { grau. }\end{array}$ & $\begin{array}{l}\text { Interpretou bem a } \\
\text { questão. Cometeu } \\
\text { erro de algébrico. }\end{array}$ \\
\hline C & $\begin{array}{l}\text { Sabe as } \\
\text { propriedades. Erro } \\
\text { nos cálculos. }\end{array}$ & $\begin{array}{l}\text { Não sabe sobre a } \\
\text { não distributividade } \\
\text { de potencias de } \\
\text { soma, mas apresenta } \\
\text { certo senso numérico. }\end{array}$ & Excelente. & $\begin{array}{l}\text { Boa interpretação. } \\
\text { Erro no trato } \\
\text { algébrico. }\end{array}$ \\
\hline E & $\begin{array}{l}\text { Não conhece as } \\
\text { propriedades, não } \\
\text { sabe somar frações. }\end{array}$ & $\begin{array}{l}\text { Conhece a hierarquia, } \\
\text { mas não sabe } \\
\text { trabalhar com } \\
\text { potência negativa. }\end{array}$ & $\begin{array}{l}\text { Pouca desenvoltura } \\
\text { no trato de frações. } \\
\text { Confundiu variável } \\
\text { independente com } \\
\text { variável dependente. }\end{array}$ & $\begin{array}{ll}\text { Boa } & \text { interpretação. } \\
\text { Erro no } & \text { trato } \\
\text { algébrico. }\end{array}$ \\
\hline
\end{tabular}


28 a 30 de SETEMBRO

\begin{tabular}{|c|c|c|c|c|}
\hline $\mathbf{F}$ & $\begin{array}{l}\text { Não sabe as } \\
\text { propriedades. }\end{array}$ & Não Fez & Não fez & Não fez \\
\hline G & Excelente & $\begin{array}{l}\text { Excelente. Pequeno } \\
\text { erro de cálculo }\end{array}$ & $\begin{array}{l}\text { Pequeno erro } \\
\text { algébrico. }\end{array}$ & Excelente. \\
\hline $\mathbf{H}$ & $\begin{array}{l}\text { Utilizou de forma } \\
\text { parcialmente correta } \\
\text { as propriedades, mas } \\
\text { não fez a letra b) da } \\
\text { questão. Problemas } \\
\text { de simplificação }\end{array}$ & $\begin{array}{l}\text { Sabe a hierarquia das } \\
\text { operações. Erros de } \\
\text { cálculo, não obstante } \\
\text { certo senso trato } \\
\text { numérico. }\end{array}$ & $\begin{array}{l}\text { Saber resolver } \\
\text { equações de segundo } \\
\text { grau. Vários erros de } \\
\text { Cálculo. }\end{array}$ & $\begin{array}{l}\text { Erro algébrico e erro } \\
\text { de interpretação. }\end{array}$ \\
\hline I & $\begin{array}{ll}\text { Não conhece } & \text { as } \\
\text { propriedades } & \text { de } \\
\text { potência e não sabe } & \text { somar frações. }\end{array}$ & Não fez & $\begin{array}{l}\text { Falta de trato } \\
\text { numérico. Não soube } \\
\text { resolver equações de } \\
\text { segundo grau. Erros } \\
\text { de conta. }\end{array}$ & $\begin{array}{l}\text { Equívocos vários. } \\
\text { Não soube } \\
\text { interpretar o } \\
\text { problema. Falta de } \\
\text { desenvoltura } \\
\text { algébrica. }\end{array}$ \\
\hline $\mathbf{J}$ & $\begin{array}{l}\text { Sabe as } \\
\text { propriedades, mas } \\
\text { não terminou a } \\
\text { questão. } \\
\text { (Insegurança?) }\end{array}$ & $\begin{array}{l}\text { Aqui utilizou as } \\
\text { propriedades de } \\
\text { forma parcialmente } \\
\text { correta. Erros de } \\
\text { Cálculo. }\end{array}$ & $\begin{array}{l}\text { Sabe resolver } \\
\text { equação de segundo } \\
\text { grau, mas não fez } \\
\text { uma questão. Erro de } \\
\text { Cálculo. }\end{array}$ & $\begin{array}{l}\text { Boa interpretação. } \\
\text { Soube diferenciar } \\
\text { variável } \\
\text { independente e } \\
\text { dependente. Erro } \\
\text { algébrico. } \\
\end{array}$ \\
\hline $\mathrm{K}$ & \begin{tabular}{|l|} 
Sabe as \\
propriedades. Não fez \\
todos os cálculos.
\end{tabular} & $\begin{array}{l}\text { Utilizou as } \\
\text { propriedades de } \\
\text { forma correta, faltou } \\
\text { um pouco de } \\
\text { percepção numérica. } \\
\text { Erros de Cálculos. } \\
\end{array}$ & Excelente & Excelente \\
\hline $\mathbf{L}$ & $\begin{array}{l}\text { Não sabe as } \\
\text { propriedades. }\end{array}$ & Não fez. & $\begin{array}{l}\text { Não sabe diferenciar } \\
\text { as variáveis } \\
\text { dependentes e } \\
\text { independentes. Não } \\
\text { sabe resolver } \\
\text { equações de segundo } \\
\text { grau. }\end{array}$ & Não fez \\
\hline $\mathbf{M}$ & $\begin{array}{l}\text { Não sabe as } \\
\text { propriedades, não } \\
\text { sabe somar frações. }\end{array}$ & $\begin{array}{l}\text { Não sabe a hierarquia } \\
\text { das operações. Falta } \\
\text { de trato numérico. }\end{array}$ & \begin{tabular}{|l} 
Não diferenciou \\
variável dependente \\
de independente. Não \\
resolveu \\
corretamente as \\
equações do segundo \\
grau, embora saiba \\
as fórmulas. \\
\end{tabular} & $\begin{array}{l}\text { Não interpretou. } \\
\text { Falta de } \\
\text { desenvoltura } \\
\text { algébrica. }\end{array}$ \\
\hline $\mathbf{N}$ & Não fez & Não fez & Não fez & Não fez \\
\hline
\end{tabular}




\begin{tabular}{|c|c|c|c|c|}
\hline 0 & $\begin{array}{l}\text { Não sabe as } \\
\text { propriedades de } \\
\text { potenciação. Não } \\
\text { sabe somar frações. }\end{array}$ & \begin{tabular}{|l} 
Sabe a hierarquia. \\
Erro de Cálculo. Falta \\
de trato numérico.
\end{tabular} & $\begin{array}{l}\text { Diferenciou variável } \\
\text { independente e } \\
\text { dependente. Não } \\
\text { soube resolver } \\
\text { equação de segundo } \\
\text { grau. }\end{array}$ & \begin{tabular}{|l} 
Não interpretou \\
corretamente. Erro \\
algébrico.
\end{tabular} \\
\hline $\mathbf{P}$ & $\begin{array}{l}\text { Não sabe as } \\
\text { propriedades de } \\
\text { potenciação e não } \\
\text { sabe somar frações. }\end{array}$ & \begin{tabular}{|l} 
Possui ideia da \\
hierarquia das \\
operações. Pouco \\
senso numérico.
\end{tabular} & $\begin{array}{l}\text { Diferenciou variável } \\
\text { independente de } \\
\text { dependente. Sabe } \\
\text { resolver equação de } \\
\text { segundo grau. }\end{array}$ & $\begin{array}{l}\text { Problema na } \\
\text { interpretação. Erro } \\
\text { algébrico. }\end{array}$ \\
\hline $\mathbf{Q}$ & $\begin{array}{l}\text { Sabe as } \\
\text { propriedades. } \\
\text { Problemas com as } \\
\text { simplificações. }\end{array}$ & $\begin{array}{l}\text { Conhece bem a } \\
\text { hierarquia das } \\
\text { operações. Não sabe } \\
\text { trabalhar com } \\
\text { potência negativa. }\end{array}$ & Excelente & $\begin{array}{l}\text { Faltou interpretação. } \\
\text { Apresentou certa } \\
\text { desenvoltura } \\
\text { algébrica. }\end{array}$ \\
\hline $\mathbf{R}$ & Excelente & $\begin{array}{l}\text { Excelente. Pequenos } \\
\text { erros. }\end{array}$ & Excelente. & $\begin{array}{l}\text { Erro de } \\
\text { interpretação. Bom } \\
\text { trato algébrico. }\end{array}$ \\
\hline S & Não fez & $\begin{array}{l}\text { Sabe a hierarquia das } \\
\text { operações, mas não } \\
\text { conhece as } \\
\text { propriedades de } \\
\text { potenciação. }\end{array}$ & $\begin{array}{l}\text { Fez a diferença entre } \\
\text { variável dependente e } \\
\text { independente. Não } \\
\text { sabe resolver } \\
\text { equação de segundo } \\
\text { grau. }\end{array}$ & Não fez \\
\hline $\mathbf{T}$ & $\begin{array}{l}\text { Sabe as propriedades } \\
\text { de potenciação. Sabe } \\
\text { operar com frações. } \\
\text { Erro de } \\
\text { distributividade. }\end{array}$ & $\begin{array}{l}\text { Sabe a hierarquia e } \\
\text { as propriedades. } \\
\text { Faltou senso } \\
\text { numérico. Erros } \\
\text { aritméticos. }\end{array}$ & $\begin{array}{l}\text { Confundiu variável } \\
\text { independente com } \\
\text { dependente } \\
\text { Sabe resolver } \\
\text { equações de segundo } \\
\text { grau. }\end{array}$ & Excelente \\
\hline $\mathbf{U}$ & $\begin{array}{l}\text { Não conhece as } \\
\text { propriedades e não } \\
\text { sabe somar frações. }\end{array}$ & $\begin{array}{l}\text { Não sabe trabalhar } \\
\text { com potências } \\
\text { negativas. Não sabe } \\
\text { somar frações. Erro } \\
\text { de Cálculo. }\end{array}$ & $\begin{array}{l}\text { Aqui somou frações } \\
\text { corretamente. Sabe } \\
\text { resolver equações do } \\
\text { segundo grau. }\end{array}$ & $\begin{array}{l}\text { Não interpretou bem } \\
\text { as questões, erro } \\
\text { algébrico. }\end{array}$ \\
\hline
\end{tabular}




\begin{tabular}{|c|l|l|l|l|}
\hline $\mathbf{V}$ & $\begin{array}{l}\text { Não conhece as } \\
\text { propriedades e não } \\
\text { sabe somar frações }\end{array}$ & $\begin{array}{l}\text { Não sabe trabalhar } \\
\text { com potências } \\
\text { negativas. Não sabe } \\
\text { somar frações. Erro } \\
\text { aritmético. }\end{array}$ & $\begin{array}{l}\text { Aqui somou frações } \\
\text { corretamente. Sabe } \\
\text { resolver equações de } \\
\text { segundo grau. }\end{array}$ & $\begin{array}{l}\text { Não interpretou bem } \\
\text { as questões. Erro } \\
\text { algébrico. }\end{array}$ \\
\hline $\mathbf{X}$ & $\begin{array}{l}\text { Ótimo. Pequeno erro } \\
\text { aritmético. }\end{array}$ & $\begin{array}{l}\text { Faltou senso } \\
\text { numérico }\end{array}$ & $\begin{array}{l}\text { Ótimo. Erro } \\
\text { aritmético. }\end{array}$ & $\begin{array}{l}\text { Faltou interpretação. } \\
\text { Bom trato algébrico. }\end{array}$ \\
\hline $\mathbf{Z}$ & $\begin{array}{l}\text { Não conhece as } \\
\text { propriedades e não } \\
\text { sabe somar frações. }\end{array}$ & $\begin{array}{l}\text { Sabe a hierarquia das } \\
\text { operações. Não sabe } \\
\text { trabalhar com } \\
\text { potências negativas. }\end{array}$ & Não fez & Não fez \\
\hline
\end{tabular}

Fonte: Elaboração própria

Foram designados como monitores os alunos G e R. Uma sala foi alocada na Instituição direcionada ao grupo de estudos. Como os alunos possuíam dois horários vagos durante a semana, esse tempo ficou reservado ao grupo. Alguns alunos, com participação efetiva no grupo de estudos, apresentaram ganhos muito significativos.

É claro que não podemos creditar esse ganho apenas ao grupo de estudos, mas também ao fato da turma possuir um número reduzido de alunos, o que permitiu por parte do professor um atendimento mais personalizado, ao empenho dos próprios estudantes, etc.

Contudo, consideramos que o grupo de estudos é uma importante variável nesse processo e que potencializa outras variáveis que favorecem o desempenho como, por exemplo, o comprometimento do discente com seu aprendizado.

A prova diagnóstica foi corrigida e pontuada.

Não obstante os alunos não tiveram acesso a notas mas apenas a correção conforme mapa apresentado. Julgamos que nesse primeiro momento a nota não seria importante, mas sim o conhecimento dos alunos de suas fragilidades. A nota foi obtida apenas para 0 percentual de acerto fosse comparado com o percentual de acerto da segunda prova, denominada pela Instituição de prova continuada, realizada 3 meses depois. Essa comparação é realizada no gráfico a seguir: 
ráfico 1 - Comparação, por aluno que participou do grupo de estudo, dos resultados da prova diagnóstica e continuada

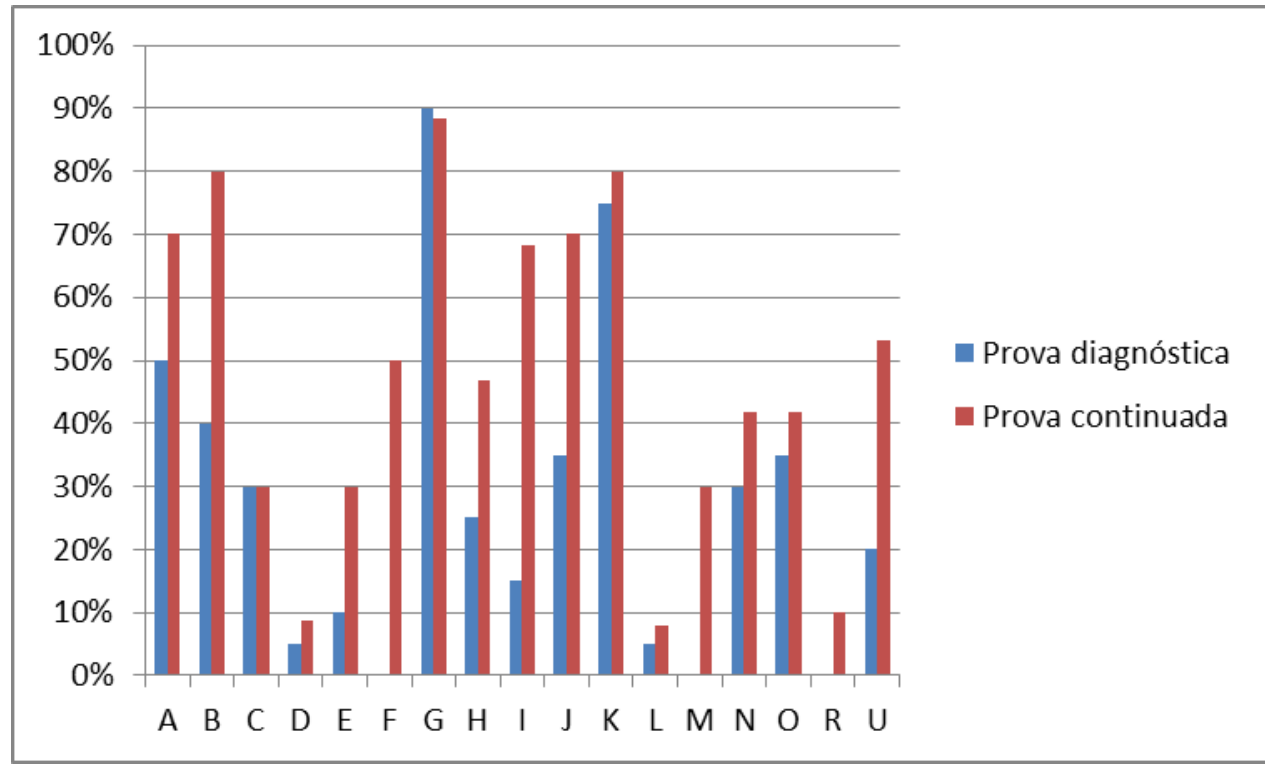

Fonte: Elaboração própria.

Neste gráfico constam as notas obtidas por 17 alunos que fizeram a prova diagnóstica e efetivamente participaram do grupo de estudo. O percentual da nota da prova diagnóstica é comparado com o percentual da prova continuada. Observamos um ganho para todos os alunos, com exceção do aluno G, que manteve, contudo, praticamente o mesmo percentual. Destacamos os alunos $B$, I e $F$ que tiveram um grande crescimento e participaram $100 \%$ do grupo de estudo. $O$ aluno $D$, contudo, teve participação em $80 \%$ dos encontros do grupo, e não apresentou um crescimento significativo, o que indica que o grupo de estudo não deve ser uma ação solitária e, claramente, não resolve todos os problemas. Mas ajuda a intendi ficar os alunos que merecem uma atenção diferenciada.

Agora, computamos os resultados dos alunos que não participaram do grupo de estudo. Foram cinco, mas dentre eles um não fez a prova continuada. Os resultados são apresentados a seguir. 
Gráfico 2 - Comparação, por aluno que não participou do grupo de estudo, dos resultados da prova diagnóstica e continuada.

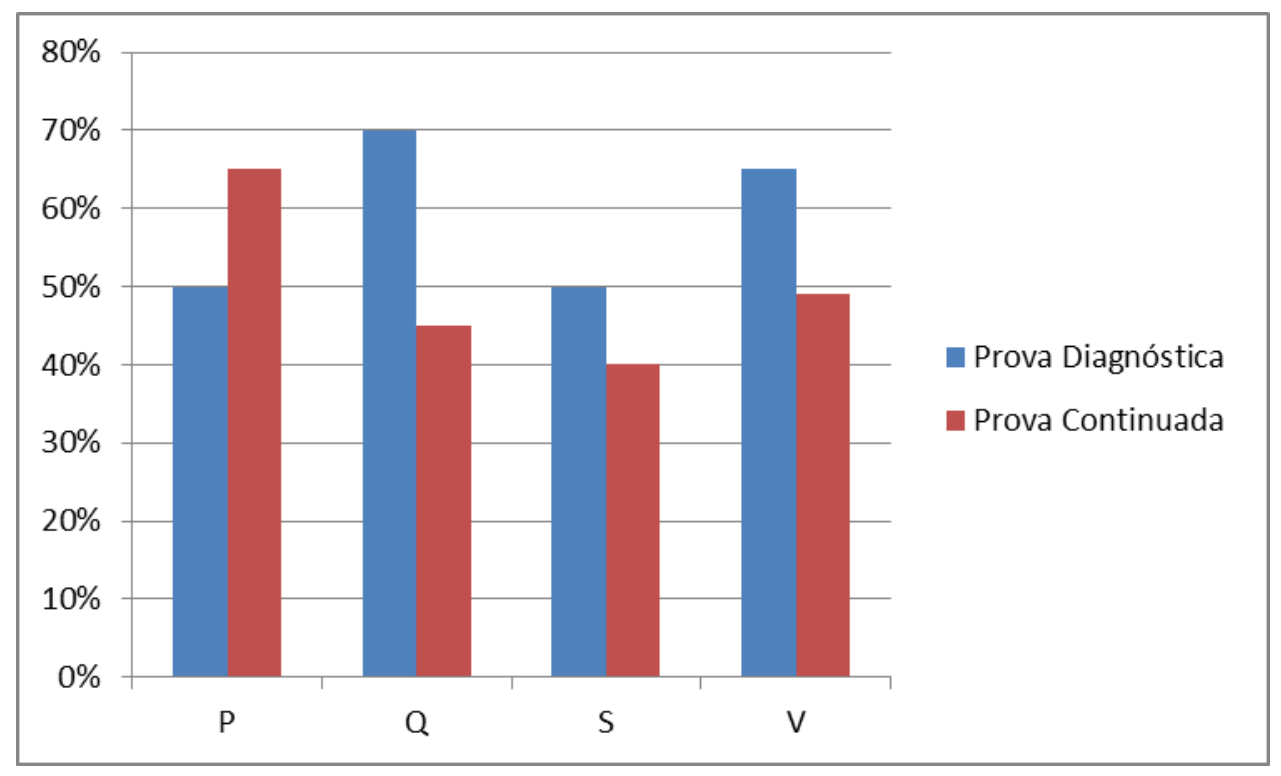

Fonte: Elaboração própria.

Observamos que não houve crescimento dos alunos, com exceção do aluno $P$. Os alunos todos, ao serem ouvidos, se manifestaram favoravelmente ao projeto.

\section{CONSIDERAÇÕES FINAIS}

O ingresso na vida universitária marca uma época de transição (COULON, 2008). Segundo Coulon a primeira fase dessa transição deve ser marcada pela filiação do estudante, o que passa pelo estabelecimento de laços com os professores, com os colegas e com a Instituição. Coulon mostra como o sucesso acadêmico e a diminuição da evasão depende, em grande medida, da capacidade de inserção ativa dos estudantes em seu novo ambiente.

Poder-se-ia argumentar que essas dificuldades são dificuldades próprias de todo começo. Contudo sabemos que a vida universitária apresenta várias rupturas com a vida do estudante do ensino médio, além de em muitos momentos coincidir com a entrada do estudante na vida adulta, o que dificulta sobremaneira esse iniciar. No nosso caso, alunos já adultos necessitam conciliar trabalho, família e estudos, o que por sua vez constitui um grande desafio. Em qualquer caso, o estreitamento dos laços com a Instituição coloca o aluno em uma posição mais vantajosa, com sensação de pertencimento. $O$ aluno, via de regra (argumenta Coulon) apresenta melhor rendimento e tende a não evadir.

Em relação ao Cálculo, DOOR ( 2017)estuda os problemas relativos ao ensino dessa disciplina, realiza um longo relato das dificuldades algébricas e conceituais dos alunos. A autora reflete sobre a impossibilidade de introduzir conceitos complexos como limites e derivadas que além da conceptualização de funções requerem maturidade em processos algébricos e intuição matemática, condições as quais os alunos prescindem. Nesse 
sentido, quase todas as propostas para melhoria do ensino de Cálculo passa pela proposta de um curso de nivelamento: Cálculo zero, Matemática básica, Pré-cálculo. Qualquer que seja a designação, esta é uma proposta bastante recorrente, que pretende instrumentalizar os alunos nos conhecimentos básicos de matemática, necessários ao prosseguimento do curso. Contudo, Rocha (2016), Dor (2017), Muller (2015), dentre outros autores, argumentam que esses cursos não apresentam o resultado esperado, que nõ existe uma aprendizagem efetiva, que será utilizada na apreensão dos conceitos do Cálculo Diferencial e Integral.

Diante desse dado da literatura, acreditamos que os conteúdos podem ser revisados (algumas vezes ensinados) em paralelo com o ensino do Cálculo, no lugar de ocuparem uma posição propedêutica.

Assim, o grupo de estudo cumpriria dupla função: Primeiro, paralelamente ao estudo da disciplina, os alunos estudariam procedimentos algébricos e numéricos, e em segundo, contudo não menos importante, estabeleceriam laços entre si, com os professores e com a Instituição.

\section{REFERÊNCIAS}

ALMEIDA, Marcio Vieira. Material para o ensino do Cálculo Diferencial e Integral: Referência de Tall, Grueudet e Trouche, 2017. Tese ( Doutorado). Curso de Educação. Pontifícia Universidade Católica de São Paulo. PUC/SP. São Paulo, 2017.

COULON, Alain. A condição de estudante: a entrada na vida universitária. Salvador: EDUFBA, 2008.

DOOR, Raquel carneiro. Análise de aprendizagem em Cálculo Diferencial e Integral: um estudo de caso de desenvolvimento de conceitos e procedimentos algébricos em uma Universidade Pública Brasileira, 2017. Tese (Doutorado) - Curso de Educação. Universidade de Brasília - UNB, Brasília, 2017.

\section{MACHADO, Nilson José Machado. Matemática e Língua Materna: análise de uma} impregnação mútua.6 edições. São Paulo: Cortez, 2011.

MULLER, Thaisa Jacinto. Objetos de aprendizagem multimodais e ensino do Cálculo: Uma proposta baseada em Na análise de erros, 2015. Tese (Doutorado). Programa de Pós-graduação em Informática na Educação. Universidade Federal do Rio Grande do Sul - UFRS- Rio Grande do Sul, 2015.

\section{RAFAEL, Rosane Cordeiro. Cálculo Diferencial e Integral: um, estudo sobre} estratégias para redução do percentual de não aprovação, 2017. Tese (Doutorado). Pós graduação em Educação Matemática. Universidade federal de Juiz de Fora - UFJF, Juiz de Fora, 2017 
ROCHA, M.M .Releitura do processo de aprendizagem de estudantes repetentes de Cálculo I. Tese ( Doutorado em Educação). Universidade Federal do espírito Santo UFES, 2016.

TEACHING OF CALCULUS AT THE ENGINEERING COURSE:

TEACHING SIMULTANEITY OF CALCULUS AND BASIC MATHEMATICS

b

It is known that the teaching of Differential and Integral Calculus present problems during the teaching learning process, and as a consequence, there are high rates of dropout and failure. Among the problems, there is a lack of knowledge of Basic Mathematics what has been proved as relevant and recurring.

This article presents a teaching simultaneity proposal of Calculus and Basic Mathematics, with the aim to mitigate students' problems as the lack of algebraic resourcefulness. The research, which was carried out in a private college, measured the algebraic resourcefulness of a group of students in the first semester of the engineering course considering the basic mathematics, and then before and after another group to which Basic Mathematics and Calculus were taught simultaneously.

The results showed very meaningful results in the students' education, besides their permanence in the institution.

KEY WORDS: Differential and Integral Calculus, Calculus Teaching, Calculus Failure. 